Marquette University

e-Publications@Marquette

Psychology Faculty Research and Publications

Psychology Department

$1-1-2015$

\title{
Maternal Functioning Differences Based on ADHD Subtype
}

Kelsey Ann Weinberger

Marquette University

Denise M. Gardner

Marquette University, denise.gardner@marquette.edu

Alyson C. Gerdes

Marquette University, alyson.gerdes@marquette.edu

Accepted version. Journal of Attention Disorders (2015): 1-6. DOI. (C) 2015 SAGE Publications. Used with permission. 


\title{
Maternal Functioning Differences Based on ADHD Subtype
}

\author{
Kelsey A. Weinberger \\ Psychology, Marquette University \\ Milwaukee, WI \\ Denise M. Gardner \\ Psychology, Marquette University \\ Milwaukee, WI \\ Alyson C. Gerdes \\ Psychology, Marquette University \\ Milwaukee, WI
}

\section{Abstract}

Objective: Maternal functioning differences in parenting stress, parental efficacy, and parenting behaviors were examined for mothers of children with ADHD.

Method: Participants included 29 mothers of children with ADHD, Predominantly Inattentive Type (ADHD-I) and 38 mothers of children with ADHD, Predominantly Hyperactive-Impulsive or Combined Type (ADHD-HI/C). 
Results: Findings suggest that mothers of children with ADHD-HI/C reported significantly greater parenting stress and engaged in more negative parenting behaviors than mothers of children with ADHD-I.

Conclusion: This study suggests that tailoring behavioral parent training based on ADHD subtype may be particularly helpful for parents of children with ADHD-HI/C.

Keywords: ADHD, parenting, ADHD subtypes

\section{Introduction}

ADHD is a common childhood disorder, which results in significant impairment in multiple domains of functioning (American Psychiatric Association [APA], 2013); however, the nature of impairment appears to be somewhat dependent on subtype (Bauermeister et al., 2005; Johnson \& Reader, 2002; Johnston \& Mash, 2001; Miranda, Marco, \& Grau, 2007). To further our understanding of potential differences in self-reported parental functioning based on ADHD subtype, the current brief report examined maternal functioning differences in parenting stress, parental efficacy, and parenting behaviors between ADHD subtypes. This line of work is important as it may result in differential treatment recommendations based on ADHD subtype (e.g., more tailored parent training interventions depending on subtype).

Current research suggests that impairment in parental functioning (i.e., parenting stress, parental efficacy, and parenting behaviors) is common among families of children with ADHD. Specifically, parents of children with ADHD report higher parenting stress and lower parental efficacy relative to parents of comparison children (Alizadeh, Applequist, \& Coolidge, 2007; Bauermeister et al., 2005; Johnson \& Reader, 2002; Johnston \& Mash, 2001; Miranda et al., 2007; Pimentel, Vieira-Santos, Santos, \& Vale, 2011; Primack et al., 2012). Research also suggests differences in parenting behaviors among mothers of children with ADHD compared with mothers of nonADHD children (Gerdes, Hoza, \& Pelham, 2003). Specifically, mothers of children with ADHD report being more controlling and disapproving, engage in less limiting setting, and are less responsive than parents of children without ADHD (Modesto-Lowe, Danforth, \& Brooks, 2008; Schroeder \& Kelley, 2009). 
Although current research highlights differences in parental functioning of parents with and without children with ADHD, less is known about possible differences among ADHD subtypes. According to a review by Milich, Balentine, and Lynam (2001), ADHD is best conceptualized as a disorder with "two distinct areas of dysfunction"inattention and hyperactivity/impulsivity, which likely lead to different behavioral presentations. For example, research has shown that children with ADHD, Predominantly Inattentive Type (ADHD-I) are likely to present as having a sluggish cognitive tempo and lethargy, whereas children with ADHD, Predominantly Hyperactive-Impulsive (ADHD-HI) and ADHD, Combined Type (ADHD-C) are likely to present as disorganized, distractible, and impulsive (Milich et al., 2001). It seems probable that these differences in behavioral presentation may impact parental functioning (Johnston \& Mash, 2001; Milich et al., 2001).

In fact, the limited research available suggests that parental functioning is more impaired in families of children with ADHD-C than ADHD-I (Bauermeister et al., 2005; Johnson \& Reader, 2002; Miranda et al., 2007). Specifically, parents of children with ADHD-C report greater family stress related to child behavior, feel more overwhelmed, and report lower parental efficacy than parents of children with ADHDI (Bauermeister et al., 2005; Johnson \& Reader, 2002; Miranda et al., 2007). To the authors' knowledge, research examining ADHD subtype differences in parenting behaviors does not exist; however, it seems likely that differences may be present given that parents of children with ADHD-C experience more child-related stress and feel less efficacious about their parenting than parents of children with ADHD-I.

Thus, the purpose of this brief report was to examine selfreported differences in maternal functioning based on ADHD subtype. It was predicted that mothers of children with ADHD-HI and ADHD-C (ADHD-HI/C) would report greater parenting stress (i.e., more parental distress, parent/child dysfunctional interaction, stress related to parenting a difficult child, and total parenting stress), lower parental efficacy, less positive parenting behaviors, and more negative parenting behaviors than mothers of children with ADHD-I.

Journal of Attention Disorders Epub ahead of print (2015). DOI. This article is (C SAGE Publications and permission has been granted for this version to appear in e-Publications@Marquette. SAGE Publications does not grant permission for this article to be further copied/distributed or hosted elsewhere without the express permission from SAGE Publications. 
NOT THE PUBLISHED VERSION; this is the author's final, peer-reviewed manuscript. The published version may be accessed by following the link in the citation at the bottom of the page.

\section{Method}

\section{Participants}

Participants included 67 children diagnosed with ADHD based on the Diagnostic and Statistical Manual of Mental Disorders (4th ed., text revision.; DSM-IV-TR; APA, 2000) and their mothers who were seen at a university-based ADHD clinic between 2005 and 2011. As part of the initial intake session, parents signed a research consent agreeing that their child's clinical file could be used for research purposes, as approved by the Institutional Review Board of the university where the clinic resides. Only children who received a diagnosis of ADHD following a comprehensive ADHD assessment were included in the current analyses.

As can be seen in Table 1 , the majority of mothers were married or cohabitating, had at least some college education, and were middle to upper-middle class based on reported socioeconomic status (SES). Children were of diverse ethnic backgrounds, ranged in age from 5 to 12 years $(M=8.16, S D=1.94)$, and were predominantly male (52 males, 15 females); the majority were not taking ADHD medication at the time of the assessment. Twenty-nine children received a diagnosis of ADHD-I, and 38 received a diagnosis of either ADHD-HI or ADHD-C; the latter two groups were combined for all analyses (ADHD-HI/C).

Journal of Attention Disorders Epub ahead of print (2015). DOI. This article is (C) SAGE Publications and permission has been granted for this version to appear in e-Publications@Marquette. SAGE Publications does not grant permission for this article to be further copied/distributed or hosted elsewhere without the express permission from SAGE Publications. 
NOT THE PUBLISHED VERSION; this is the author's final, peer-reviewed manuscript. The published version may be accessed by following the link in the citation at the bottom of the page.

Table 1. Mother and Child Demographics.

\begin{tabular}{|c|c|c|c|}
\hline & ADHD-1 $(n=29)$ & ADHD-HUC $(n=38)$ & Tocal $(N=67)$ \\
\hline \multicolumn{4}{|l|}{ Mother demographics } \\
\hline \multicolumn{4}{|l|}{ Marical status, $n\left(\boldsymbol{X}_{)}\right.$} \\
\hline Married/cohabieating & $17(59)$ & $30(79)$ & $47(70)$ \\
\hline Single'never married/divorced & $12(41)$ & $8(21)$ & $20(30)$ \\
\hline \multicolumn{4}{|l|}{ Education, $n(\%)$} \\
\hline Less than high school & I (3) & $2(5)$ & $3(4)$ \\
\hline Graduated high schoolvGED & $4(14)$ & $11(29)$ & $15(22)$ \\
\hline Some college/training & $7(24)$ & $6(16)$ & $13(19)$ \\
\hline College or graduate degree & $17(59)$ & $16(42)$ & $33(49)$ \\
\hline Socioeconomic status $(M, S D)$ & $47.3(13.4)$ & $43.32(15.1)$ & $45.2(14.1)$ \\
\hline \multicolumn{4}{|l|}{ Child demographics } \\
\hline \multicolumn{4}{|l|}{ Echnicity, $n(x)^{*}$} \\
\hline Caucasian & $22(76)$ & $16(42)$ & $38(57)$ \\
\hline Non-Caucasian & $7(24)$ & $22(58)$ & $29(43)$ \\
\hline Black & $2(7)$ & $7(18)$ & $9(13)$ \\
\hline Hispanic & $3(10)$ & $7(18)$ & $10(15)$ \\
\hline Other & $2(7)$ & $8(21)$ & $10(15)$ \\
\hline$A g e(M, S D)^{*}$ & $9.00(1.85)$ & $7,53(1,77)$ & $8.16(1.94)$ \\
\hline \multicolumn{4}{|l|}{ Gender, $n(x)$} \\
\hline Boys & $19(66)$ & $33(87)$ & $52(78)$ \\
\hline Girls & $10(34)$ & $5(13)$ & $15(22)$ \\
\hline \multicolumn{4}{|l|}{ ADHD medication status } \\
\hline Yes & $22(76)$ & $28(74)$ & $50(83)$ \\
\hline No & $5(17)$ & 7 (18) & $12(18)$ \\
\hline
\end{tabular}

Note. ADHD-I $=$ ADHD, Predominantly Inattentive Type; ADHD-HI/C $=$ ADHD, Predominantly Hyperactive-Impulsive or Combined Type; GED = General Educational Development.

$* p \leq .05$.

\section{Assessment and Diagnostic Information}

All children received a comprehensive evaluation at a universitybased ADHD clinic. As part of the evaluation, parents responded to an unstructured interview aimed at gathering information about the presenting problem, as well as relevant family, social, developmental, and medical history. Parents also responded to the Parent Structured Interview for Disruptive Behavior Disorders (DBD; Pelham, 2002). Parents also completed several child behavior questionnaires, as well as measures of parental/family functioning. Children responded to an unstructured interview and completed several self-report measures. Finally, classroom teachers responded to an unstructured interview and completed several child behavior questionnaires; a structured classroom observation was also completed by a trained clinician. Diagnostic decisions were made by clinical psychology PhD students 
and a faculty expert on childhood ADHD. Decisions were informed based on the presenting problem, behavioral observations, parent and teacher responses on the Parent/Teacher DBD Rating Scale (Pelham, Gnagy, Greenslade, \& Milich, 1992), and parent responses to the DBD interview.

\section{Measures}

\section{Client information form}

A client information form was completed by the primary caregiver to gather basic demographic information, such as child age, sex, ethnicity, and parental education and occupation.

\section{Parenting Stress Index-Short Form (PSI-SF)}

The PSI-SF (Abidin, 1995) is a 36-item measure of parenting stress with three subscales, Parental Distress, Parent/Child Dysfunctional Interaction, and Difficult Child, as well as a Total Parenting Stress score. Items are on a 5-point scale ranging from strongly agree to strongly disagree, with higher scores representing more parenting stress. An example item is, "I often have the feeling that I cannot handle things very well." The PSI-SF has demonstrated good internal consistency and construct validity (Whiteside-Mansell et al., 2007). The Total Parenting Stress score on the PSI demonstrated good internal consistency for the current sample $(a=.92)$, with subscale (i.e., Parental Distress, Parent/Child Dysfunctional Interaction, and Difficult Child) alphas ranging from .81 to .87.

\section{Parenting Sense of Competence Scale (PSOC)}

The Parenting Efficacy subscale of the PSOC (Johnston \& Mash, 1989) assesses parental efficacy. Mothers rated seven items on a 6point scale ranging from strongly agree to strongly disagree, with higher scores indicating higher parental efficacy. An example item is, "I honestly believe I have all the skills necessary to be a good parent to my child." Previous research has demonstrated good internal consistency (Johnston \& Mash, 1989) and adequate validity (Ohan, 
Leung, \& Johnston, 2000). The internal consistency for the current sample was .90.

\section{Alabama Parenting Questionnaire (APQ)}

The APQ (Shelton, Frick, \& Wootton, 1996) is a 42-item parentreport measure of parenting practices. Mothers rated each item on a 5-point scale; five domains were examined in the current study, including Involvement (e.g., "You play games or do other fun things with your child"), Positive Parenting (e.g., "You let your child know when he or she is doing a good job with something"), Poor Monitoring/Supervision (e.g., "You get so busy that you forget where your child is and what he or she is doing"), Inconsistent Discipline (e.g., "You threaten to punish your child and then do not actually punish him or her"), and Corporal Punishment (e.g., "You yell or scream at your child when he or she has done something wrong"); higher scores in each domain are indicative of higher frequency of that parenting behavior. Shelton and colleagues (1996) have demonstrated adequate reliability and validity for most subscales of the measure. In the current study, subscales of the APQ were collapsed to create a positive parenting scale (Involvement and Positive Parenting) and a negative parenting scale (Poor Monitoring/Supervision, Inconsistent Discipline, and Corporal Punishment), given the highly correlated nature of the subscales. The positive parenting and negative parenting scales demonstrated good internal consistency (as $=.82$ and .79 , respectively).

\section{Results}

Preliminary analyses included examination of potential demographic differences between our two groups. Specifically, a series of chi-square tests for independence (with Yates Continuity Correction) were conducted to assess differences in maternal marital status and education, as well as child ethnicity and gender. A chi-square test indicated a significant association between child ethnicity and ADHD subtype; the ADHD-I group included fewer non-Caucasian and more Caucasian children than would be expected, and the ADHD-HI/C group included more non-Caucasian and fewer Caucasian children than would be expected. No other differences emerged (see Table 1). Similarly, 
two independent-samples $t$ tests were conducted to compare child age and SES between our two groups. As illustrated in Table 1, a significant difference emerged for child age. Examination of the means indicated that children with ADHD-HI/C were significantly younger than children with ADHD-I.

To determine whether child ethnicity or age should be controlled for in the primary analyses, correlations were conducted to examine the relation between child ethnicity and age and the dependent variables (i.e., parenting stress-parental distress, parent/child dysfunctional interaction, difficult child, and total parenting stress; parental efficacy; positive parenting behavior; and negative parenting behavior). Three significant correlations emerged. Child ethnicity was significantly related to parental efficacy $(r=-.27, p \leq .05)$; mothers of non-Caucasian children reported greater parental efficacy than mothers of Caucasian children. Child age was significantly related to positive parenting $(r=-.36, p \leq .01)$ and negative parenting $(r=.27$, $p \leq .05)$; mothers of younger children reported more positive parenting and less negative parenting behaviors than mothers of older children.

Based on preliminary analyses, four one-way-between groups ANOVAs and three one-way between-groups ANCOVAs were conducted. The ANOVAs compared mothers of children with ADHD-I with mothers of children with ADHD-HI/C on parenting stress (i.e., parental distress, dysfunctional parent/child interaction, difficult child, and total parenting stress). As can be seen in Table 2, significant differences emerged for stress related to parenting a difficult child and total parenting stress. Examination of the means indicated that mothers of children with ADHD-HI/C reported greater levels of stress related to parenting a difficult child and greater total parenting stress than mothers of children with ADHD-I. Using Cohen's $d$, all effect sizes were medium.

Journal of Attention Disorders Epub ahead of print (2015). DOI. This article is (C) SAGE Publications and permission has been granted for this version to appear in e-Publications@Marquette. SAGE Publications does not grant permission for this article to be further copied/distributed or hosted elsewhere without the express permission from SAGE Publications. 
NOT THE PUBLISHED VERSION; this is the author's final, peer-reviewed manuscript. The published version may be accessed by following the link in the citation at the bottom of the page.

Table 2. Maternal Functioning Differences Between Mothers of Children With ADHD-I and Mothers of Children With ADHD-HI/C.

\begin{tabular}{|c|c|c|c|c|}
\hline & ADHD-1 & ADHD-HI/C & $f$ & Cohen's d \\
\hline \multicolumn{5}{|l|}{ Maternal parenting stress $(M, 5 D)$} \\
\hline Parental distress & $22.48(6.34)$ & $24.82(8.62)$ & 1.50 & 0.31 \\
\hline Dysfunctional interaction & $23.34(5.83)$ & $25.26(7.73)$ & 1.24 & 0.28 \\
\hline Difficult child & $31.03(8.00)$ & $36.29(8.28)$ & $6.83^{*}$ & 0.65 \\
\hline Tocal stress & $75.86(15.37)$ & $86.37(21.46)$ & $4.09 *$ & 0.56 \\
\hline Maternal parental efficacy (M SD) & $4.04(1.00)$ & $4.15(1.01)$ & 0.04 & 0.11 \\
\hline \multicolumn{5}{|l|}{ Matemal parenting practices $(M, S D)$} \\
\hline Positive parenting & $65.07(6.00)$ & $64.44(8.20)$ & 2.86 & 0.04 \\
\hline Negative parenting & $32.55(6.12)$ & $34.74(7.30)$ & $6.13^{*}$ & 0.33 \\
\hline
\end{tabular}

Note, $0.2=$ smul effect, $0.5=$ medium effect, $0.8=$ arge effect (Cohen, 1988 ). ADHD. $1=$ ADHD, Predominantly Inattentive Type; ADHD.HI/C = ADHD, Predeminansty Hyperactive-Impulive or Combined Type. $p \leq .05$

Note. $0.2=$ small effect, $0.5=$ medium effect, $0.8=$ large effect (Cohen, 1988) . ADHD-I = ADHD, Predominantly Inattentive Type; ADHD-HI/C = ADHD, Predominantly Hyperactive-Impulsive or Combined Type.

$* p \leq .05$.

The first ANCOVA compared the two groups of mothers on parental efficacy while controlling for child ethnicity. The main effect and interaction for child ethnicity were not significant; thus, only the means for group are reported in Table 2. As can be seen in Table 2, the main effect for group was not significant after controlling for child ethnicity. The second and third ANCOVA compared mothers of children with ADHD-I with mothers of children with ADHD-HI/C on positive parenting behaviors (i.e., involvement, positive parenting) and negative parenting behaviors (i.e., corporal punishment, inconsistent discipline, poor monitoring), while controlling for child age. The main effects for child age and both interactions were not significant; thus, only the means for group are reported in Table 2. As can be seen in Table 2, after controlling for child age, the main effect for group emerged as significant for negative parenting behaviors but not positive parenting behaviors. Examination of the means indicated that mothers of children with ADHD-HI/C reported engaging in more negative parenting behaviors than mothers of children with ADHD-I; the effect size was small.

\section{Discussion}

The current study examined self-reported differences in parental functioning in mothers of children with different ADHD subtypes. As predicted, mothers of children with ADHD-HI/C reported significantly

Journal of Attention Disorders Epub ahead of print (2015). DOI. This article is (C) SAGE Publications and permission has been granted for this version to appear in e-Publications@Marquette. SAGE Publications does not grant permission for this article to be further copied/distributed or hosted elsewhere without the express permission from SAGE Publications. 
greater parenting stress and engaged in more negative parenting behaviors than mothers of children with ADHD-I. This supports the need for consideration of differential treatment recommendations for different subtypes of ADHD.

The finding of greater parenting stress in mothers of children with ADHD-HI/C relative to mothers of children with ADHD-I suggests that hyperactivity and impulsivity elicit more parenting stress than inattention alone. It may be that the on-the-go behavior and poor selfcontrol exhibited by children with ADHD-HI/C create more chaos in the home and are more difficult to manage than the inattention exhibited by children with ADHD-I. Although not directly examined in the current study due to sample size, this finding also suggests that comorbid externalizing behaviors (e.g., aggression and argumentativeness), which are more often found in children with ADHD-HI/C than children with ADHD-I (Milich et al., 2001), may place more demands on parents of children with ADHD-HI/C relative to parents of children with ADHD-I, resulting in greater parenting stress.

The finding of greater negative parenting behaviors reported by mothers of children with ADHD-HI/C relative to mothers of children with ADHD-I suggests that mothers of children with hyperactivity/impulsivity reported monitoring their children less and engaging in more unpredictable and harsher parenting than mothers of children with ADHD-I. It is possible that children with more overt behavioral problems lead to greater frustration and less patience in parents, which may result in the use of harsher and more inconsistent parenting behaviors than parents of children who display only inattentive behaviors. This is consistent with previous research demonstrating that mothers of difficult-to-manage children are more likely to respond with force and use harsher discipline practices than comparison mothers (Johnston \& Mash, 2001; Woodward, Taylor, \& Dowdney, 1998).

Several limitations of the current study should be noted. Analyses focused solely on mothers of children with ADHD due to a limited number of participating fathers. Given that few studies have examined paternal functioning in families of children with ADHD, it is important to increase participation of fathers in research to extend the current findings. Due to sample size, comorbidity was also not 
examined within the sample. Given that $29 \%$ to $50 \%$ of children with ADHD meet diagnostic criteria for another disorder (Booster, DuPaul, Eiraldi, \& Power, 2010; Spencer, Biederman, \& Mick, 2007), examining the impact of comorbid diagnoses on parental functioning in a larger sample would be worthwhile.

In summary, this study suggests that tailoring behavioral parent training based on ADHD subtype may be particularly helpful for parents of children with ADHD-HI/C. In the current study, these mothers reported both a higher level of parenting stress and the use of more negative parenting behaviors than mothers of children with ADHD-I. Although there is a significant focus on teaching parents more effective discipline strategies (e.g., time-out, natural consequences, and removal of privileges) in standard behavioral parent training, it is very possible that a high level of parenting stress may not allow some parents (e.g., parents of children with ADHD-HI/C) to actually implement these new strategies. Research has clearly demonstrated that parents turn to harsher parenting strategies more often when they are experiencing high levels of negative affect, such as stress (Dix, 1991; Dix \& Lochman, 1990). Unfortunately, standard behavioral parent training typically does not address parenting stress directly.

The current findings suggest that adding even a few sessions directly targeting parenting stress may be particularly helpful for parents of children with ADHD-HI/C. Sessions could focus both on psychoeducation related to parenting stress and discipline strategies, as well as education regarding specific tools that parents can use in the moment to reduce their negative affect, which will likely increase the likelihood that they will be able to employ the new parenting strategies they have been learning. The strategies taught could be as simple as teaching parents diaphragmatic breathing and cognitive reframing. Chronis and colleagues have already demonstrated improvements in the functioning of mothers of children with ADHD following a cognitive-behavioral intervention for depression (Chronis, Chacko, Fabiano, Wymbs, \& Pelham, 2004; Chronis, Gamble, Roberts, \& Pelham, 2006), suggesting that integrating some of these techniques into standard behavioral parent training could be helpful for some parents.

Journal of Attention Disorders Epub ahead of print (2015). DOI. This article is (C) SAGE Publications and permission has been granted for this version to appear in e-Publications@Marquette. SAGE Publications does not grant permission for this article to be further copied/distributed or hosted elsewhere without the express permission from SAGE Publications. 
NOT THE PUBLISHED VERSION; this is the author's final, peer-reviewed manuscript. The published version may be accessed by following the link in the citation at the bottom of the page.

Declaration of Conflicting Interests The author(s) declared no potential conflicts of interest with respect to the research, authorship, and/or publication of this article.

Funding The author(s) received no financial support for the research, authorship, and/or publication of this article.

\section{References}

Abidin R. R. (1995). Parenting Stress Index (3rd ed.). Lutz, FL: Psychological Assessment Resources.

Alizadeh H., Applequist K. F., Coolidge F. L. (2007). Parental selfconfidence, parenting styles, and corporal punishment in families of children with ADHD in Iran. Child Abuse \& Neglect, 31, 567-572. doi:10.1016/j.chiabu.2006.12.005

American Psychiatric Association. (2000). Diagnostic and statistical manual of mental disorders (4th ed., text rev.). Washington, DC: Author.

American Psychiatric Association. (2013). Diagnostic and Statistical Manual of Mental Disorders (5th ed.). Arlington, VA: American Psychiatric Publishing.

Bauermeister J. J., Matos M., Reina G., Salas C. C., Martinez J. V., Cumba E., Barkley R. A. (2005). Comparison of DSM-IV combined and inattentive types of ADHD in a school-based sample of Latino/Hispanic children. Journal of Child Psychology and Psychiatry, 46, 166-179. doi:10.1111/j.1469-7610.2004.00343.x

Booster G. D., DuPaul G. J., Eiraldi R., Power T. J. (2010). Functional impairments in children with ADHD: Unique effects of age and comorbid status. Journal of Attention Disorders, 16, 179-189. doi: 1087054710383239

Chronis A. M., Chacko A., Fabiano G. A., Wymbs B. T., Pelham W. E.Jr. (2004). Enhancements to the behavioral parent training paradigm for families of children with ADHD: Review and future directions. Clinical Child and Family Psychology Review, 7, 1-27.

Chronis A. M., Gamble S. A., Roberts J. E., Pelham W. E.Jr. (2006). Cognitive-behavioral depression treatment for mothers of children with attention-deficit/hyperactivity disorder. Behavior Therapy, 37, 143-158.

Cohen J. (1988). Statistical power analysis for the behavioral sciences (2nd ed.). Mahwah, NJ: Erlbaum.

Journal of Attention Disorders Epub ahead of print (2015). DOI. This article is (C) SAGE Publications and permission has been granted for this version to appear in e-Publications@Marquette. SAGE Publications does not grant permission for this article to be further copied/distributed or hosted elsewhere without the express permission from SAGE Publications. 
NOT THE PUBLISHED VERSION; this is the author's final, peer-reviewed manuscript. The published version may be

accessed by following the link in the citation at the bottom of the page.

Dix T. (1991). The affective organization of parenting: Adaptive and maladaptive processes. Psychological Bulletin, 110, 3-25.

Dix T., Lochman J. E. (1990). Social cognition and negative reactions to children: A comparison of mothers of aggressive and nonaggressive boys. Journal of Social \& Clinical Psychology, 9, 418-438.

Gerdes A. C., Hoza B., Pelham W. E. (2003). Attention-deficit/hyperactivity disordered boys' relationships with their mothers and fathers: Child, mother, and father perceptions. Development and Psychopathology, 15, 363-382. doi:10.1017.S0954579403000208

Johnson J. H., Reader S. K. (2002). Assessing stress in families of children with ADHD: Preliminary development of the Disruptive Behavior Stress Inventory (DBSI). Journal of Clinical Psychology in Medical Settings, 9, 51-62. doi:10.1023/a:1014136029697

Johnston C., Mash E. J. (1989). A measure of parenting satisfaction and efficacy. Journal of Clinical Child Psychology, 18, 167-175. doi: $10.1207 /$ s15374424jccp1802_8

Johnston C., Mash E. J. (2001). Families of children with attentiondeficit/hyperactivity disorder: Review and recommendations for future research. Clinical Child and Family Psychology Review, 4, 183207. doi:10.1023/a:1017592030434

Milich R., Balentine A. C., Lynam D. R. (2001). ADHD combined type and ADHD predominantly inattentive type are distinct and unrelated disorders. Clinical Psychology: Science and Practice, 8, 463-506. doi: $10.1093 /$ clipsy.8.4.463

Miranda A., Marco R., Grau D. (2007). Parenting stress in families of children with attention-deficit/hyperactivity disorder: The impact of ADHD subtype and oppositional defiant disorder comorbidity. Advances in Learning and Behavioral Disabilities, 20, 139-162. doi:10.1016/S0735-004x(07)20006-0

Modesto-Lowe V., Danforth J. S., Brooks D. (2008). ADHD: Does parenting style matter? Clinical Pediatrics, 47, 865-872. doi: $10.1177 / 0009922808319963$

Ohan J. L., Leung D. W., Johnston C. (2000). The Parenting Sense of Competence scale: Evidence of a stable factor structure and validity. Canadian Journal of Behavioural Science/Revue canadienne des sciences du comportement, 32(4), 251. doi:10.1037/h0087122

Pelham W. E. (2002). Attention deficit hyperactivity disorder: Diagnosis, assessment, nature, etiology, and treatment. Unpublished manuscript, State University of New York at Buffalo.

Pelham W.E., Gnagy E.M., Greenslade K.E., Milich R. (1992). Teacher ratings of DSM-III-R symptoms for the disruptive behavior disorders.

Journal of Attention Disorders Epub ahead of print (2015). DOI. This article is (C SAGE Publications and permission has been granted for this version to appear in e-Publications@Marquette. SAGE Publications does not grant permission for this article to be further copied/distributed or hosted elsewhere without the express permission from SAGE Publications. 
NOT THE PUBLISHED VERSION; this is the author's final, peer-reviewed manuscript. The published version may be accessed by following the link in the citation at the bottom of the page.

Journal of American Academy of Child and Adolescent Psychiatry, 31, 210-218. doi:10.1097/00004583-199203000-00006

Pimentel M. J., Vieira-Santos S., Santos V., Vale M. C. (2011). Mothers of children with attention-deficit/hyperactivity disorder: Relationship among parenting stress, parenting stress, and child behaviour. Attention Deficit Hyperactivity Disorders, 3, 61-68. doi:10.1007/s12402-011-0053-3

Primack B. A., Hendricks K. M., Longacre M. R., Adachi-Mejia A. M., Weiss J. E., Titus L. J., . . .Dalton M. A. (2012). Parental efficacy and child behavior in a community sample of children with and without attention-deficit hyperactivity disorder (ADHD). ADHD Attention Deficit and Hyperactivity Disorders, 4, 189-197. doi:10.1007/s12402-012-0089-z

Schroeder V. M., Kelley M. L. (2009). Associations between family environment, parenting practices, and executive functioning of children with and without ADHD. Journal of Child and Family Studies, 18, 227-235. doi: 10.1007/s10826-008-9223-0

Shelton K. K., Frick P. J., Wootton J. M. (1996). Assessment of parenting practices in families of elementary school-age children. Journal of Clinical Child Psychology, 25, 317-329. doi:10.1207/s15374424jccp2503_8

Spencer T. J., Biederman J., Mick E. (2007). Attention-deficit/hyperactivity disorder: Diagnosis, lifespan, comorbidities, and neurobiology. Ambulatory Pediatrics, 7, 73-81. doi:10.1093/jpepsy/jsm005

Whiteside-Mansell L., Ayoub C., McKelvey L., Faldowski R. A., Hart A., Shears J. (2007). Parenting stress of low-income parents of toddlers and preschoolers: Psychometric properties of a short form of the Parenting Stress Index. Parenting: Science and Practice, 7, 26-56. doi:10.1080/15295190709336775

Woodward L., Taylor E., Dowdney L. (1998). The parenting and family functioning of children with hyperactivity. Journal of Child Psychology and Psychiatry, 39, 161-169.

Journal of Attention Disorders Epub ahead of print (2015). DOI. This article is (C) SAGE Publications and permission has been granted for this version to appear in e-Publications@Marquette. SAGE Publications does not grant permission for this article to be further copied/distributed or hosted elsewhere without the express permission from SAGE Publications. 